\title{
INVESTIGATING THE BEHAVIOR OF BOUNDARY ELEMENTS IN STEEL SHEAR WALLS WITH DIFFERENT CONNECTIONS
}

\author{
Bi Ying \\ Zheng Zhou Sheng Da University Of Economics, Business \& Management; \\ Zhengzhou Henan, 451191 China, biyingsu@126.com
}

\begin{abstract}
In the recent five decades, steel shear walls have been one of the most important systems in the construction and rehabilitation of many structures. The system has many advantages, including high strength and stiffness, high ductility, and excellent energy dissipation capacity. Steel shear walls are made and executed in different types. These include walls with and without stiffeners as well as composites. Recent research shows that they are a type of steel shear wall in which the infill plate is slightly away from the boundary members. In fact, there is no connection between the infill plate and one of the boundary members. Therefore, in this study, the behavior of traditional one-story-one-span steel shear walls with four different lengths was investigated numerically using ABAQUS software. For comparison, walls in which the sheet was attached only to a beam or column were examined. Obtained results from the study showed that the lateral bearing capacity of samples with free beam or free column is less than that of samples with full connection, on average $20 \%$. Also, the strength of the samples with the free column is slightly higher than the samples with the free beam. In addition, boundary members, especially columns, are much less affected by forces in free-column specimens than in other specimens, decreasing economic costs.
\end{abstract}

\section{KEYWORDS}

Steel structures, Steel shear walls (SSWs), Inserting plate, Numerical analysis, ABAQUS software

\section{INTRODUCTION}

Previous research has shown several advantages for steel shear walls, including high stiffness and strength, good ductility, higher energy dissipation capacity, fast construction, and economic savings [1, 2]. The main factor of lateral load strength in a steel shear wall system is the infill plate. Steel shear walls in their traditional type have defects such as premature buckling of the plate. This phenomenon subsequently reduces the energy dissipation capacity of the system, which can also reduce ductility. A steel shear wall typically consists of a thin sheet of steel enclosed in boundary members, including beams and columns. Web-plates can also be with or without stiffeners depending on the design conditions. Steel shear walls resist lateral loads by creating diagonal tensile fields in the infill plate. In order to fully utilize the capacity of the plate, a diagonal tension field action must be uniformly formed in it. Achieving such a goal requires that the boundary elements, especially the columns, must have a very high bending stiffness [3, 4]. The use of very strong columns in terms of bending stiffness makes the design look uneconomical and heavy. To overcome this problem, a special type of steel shear wall has recently been proposed in which the plate is somewhat separated from the main columns and attached to a sub-column that can be weak and semi-strong. Ultimately, this reduces the size of the main column to an economical design. The first research in this field began in the numerical research performed by 
Xue and Lu $[5,6]$. They found that using a steel shear wall in which the plate is attached only to the beam reduces the forces acting on the columns. To better understand the behavior of steel shear walls with partial connection, many researchers have conducted numerous experimental and numerical studies. Some of the research on the above topic is briefly presented. In 2008, Hoi and Park tested a new type of steel shear wall called a steel shear wall with a partial connection. The infill plate in this system was only connected to the beams, and the columns were free [7]. In order to compare the behavior of this sample, they examined a typical steel shear wall while maintaining the geometric conditions of the boundary elements and the mechanical conditions of the infill plate. The result of the experiments was that the samples had the same initial hardness, but the final strength of the sample with partial connection was less than the final strength of the sample with the full connection. The energy absorption of the sample with cross-linking was also reported to be about $65 \%$ of the energy absorption of the sample with the full connection. But, acting forces on the columns of the still shear wall (SSW) with partial connection was reduced considerably. In 2011, Guo et al. Examined steel shear walls in which infill plate was attached only to beams [8]. The results of these experiments showed that the studied systems have good ductility and excellent energy dissipation capacity. They also studied the effect of height-to-thickness and widthto-height ratios. Therefore, obtained results showed that these values significantly affected the hysteresis behavior of the system.

\section{Validation}

In this section, to validate the results of this research, firstly, two laboratory models were validated using ABAQUS finite element software. The first laboratory sample used in this study is related to the experiment performed by Choi and Park [9]. During this experiment, a 3-story singlebay $2 \mathrm{D}$ frame was subjected to lateral cyclic loading. It is worth mentioning that to apply plate buckling in this model, an initial imperfection was considered according to the first buckling mode. To investigate the behavior of this laboratory sample, a cyclic load was inserted into the last floor column once. Figure 1 shows the hysteresis curve of the laboratory model and the results obtained from the numerical simulation.

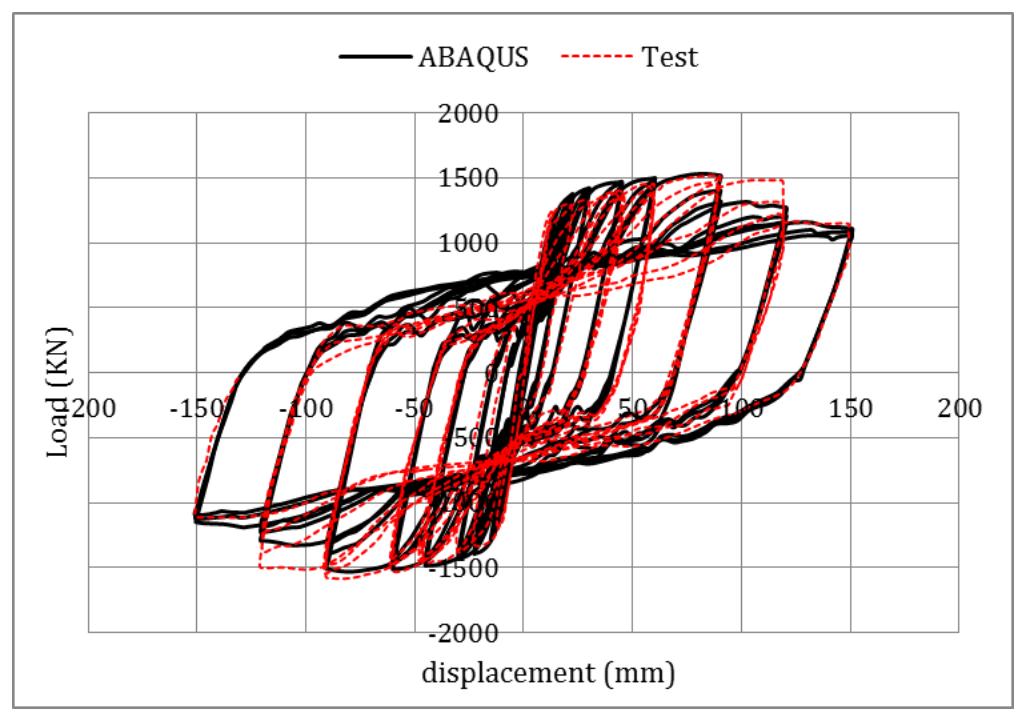

Fig. 1 - hysteresis curve of test and finite element of FSPW3 sample

The strength of the laboratory sample in the positive and negative directions of loading is 1500 and $1565 \mathrm{kN}$, respectively. On the other hand, the strength of the finite element model is 1529 and $1531 \mathrm{kN}$, respectively, in the positive and negative directions. Thus, the difference between the maximum strength of finite element and laboratory models for this sample in positive and negative directions is $1.9 \%$ and $2.3 \%$, respectively. Therefore, ABAQUS software can predict 
the behavior of this system well. Figure 2 and Figure 3 show the deformation of the laboratory specimen and the finite element model of this sample at the end of loading. According to Choi et al., In the test sample, the sample failure was primarily due to the suction of the column because of the post-buckling field of the plate on the first floor and finally, the failure of the column foot connection. As can be seen, the deformation of the finite element model and the laboratory model is very close to each other. In particular, the formation of plastic joints in the laboratory model is well reflected in the finite element model.

a

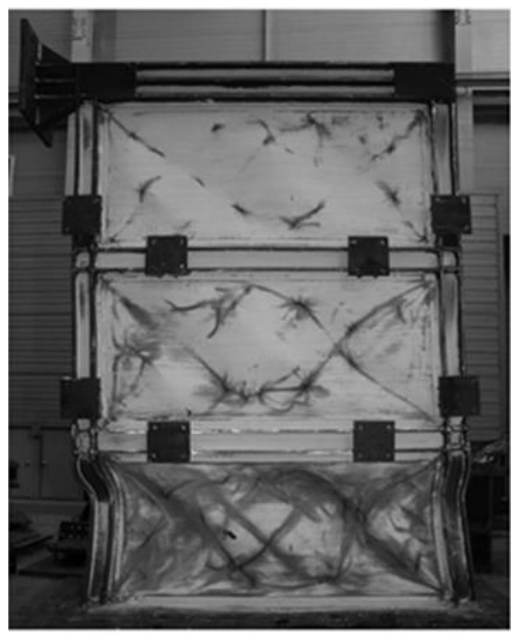

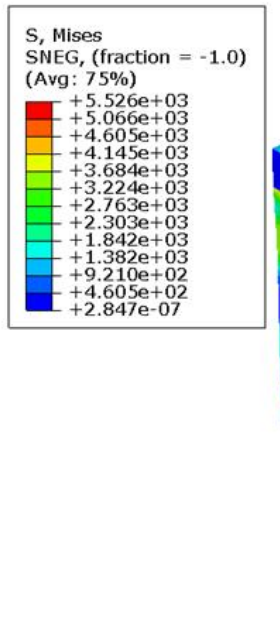

$\mathrm{b}$

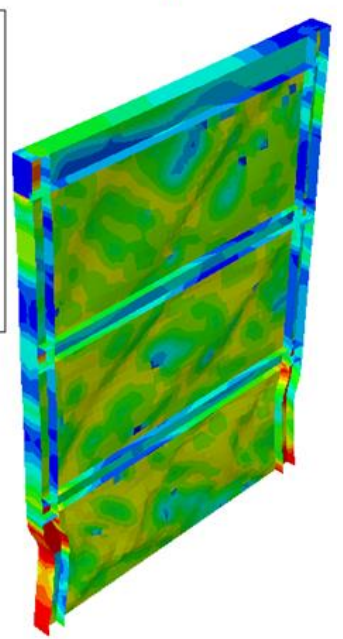

Fig. 2 - Deformation of test and finite element model

\section{A: Experiment b: finite element}

The next laboratory sample for validation is the experiment performed by Park et al. [10]. During this experiment, a 3-story single-bay frame was subjected to cyclic loading (see Figure 3).

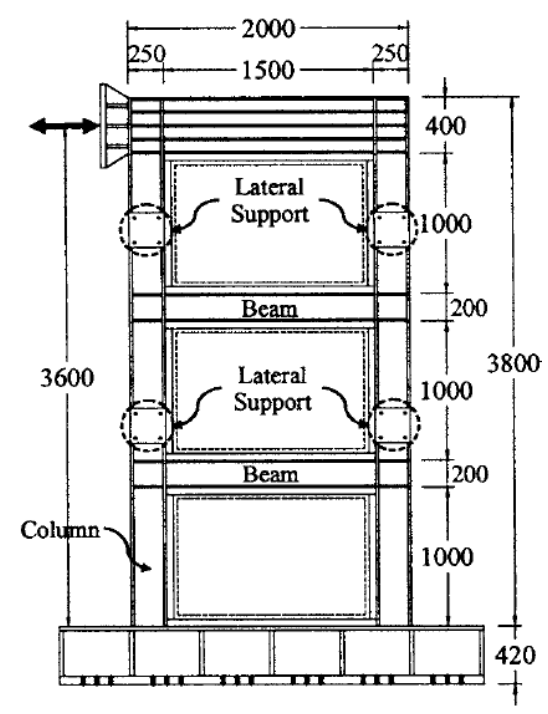

Fig. 3 - Schematic of laboratory sample [10]

Figure 4 shows the hysteresis curve of the laboratory model and the finite elements of the sample. 


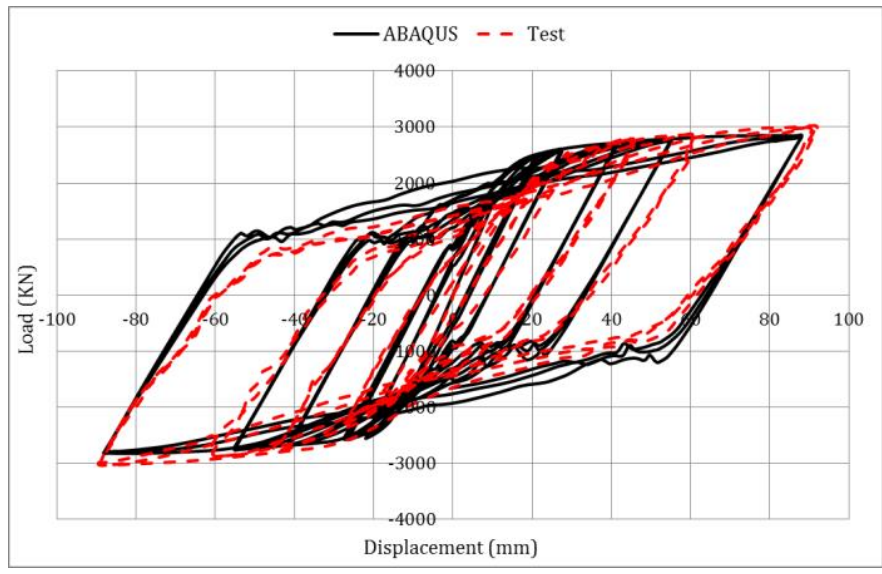

Fig .4 - hysteresis curve of the laboratory model and the finite elements

The strength of the laboratory sample in positive and negative directions is 2992 and 3021 $\mathrm{kN}$, respectively. The strength of the finite element model in the positive and negative directions is 2847 and $2824 \mathrm{kN}$, respectively. Thus, the difference between the ultimate strength of finite element and laboratory models in the positive and negative directions of loading is $5 \%$ and $7 \%$, respectively. In general, there is a good agreement between the hysteresis curve obtained from experimental and finite element modeling. Figure 5 shows the deformation of the laboratory sample and the finite element of SC6T at the end of loading. As can be seen, the deformation of the finite element model and the laboratory model is very close to each other. In particular, the formation of plastic hinges at the base column in the laboratory model is well reflected in the finite element model.
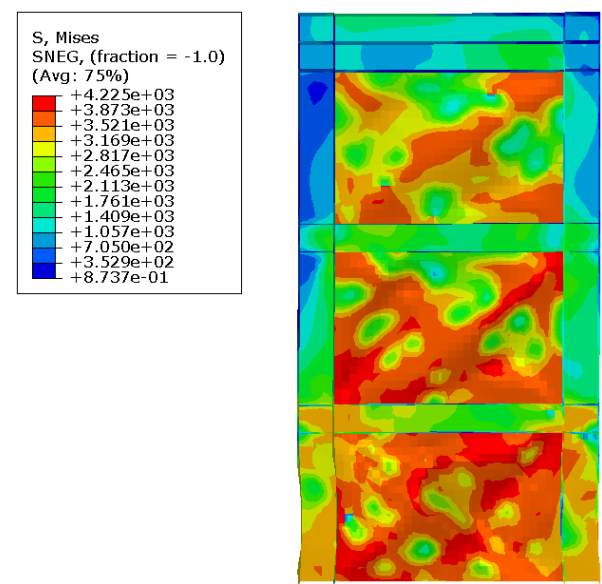

Fig .5 - Deformation of the SC6T sample in the end of loading

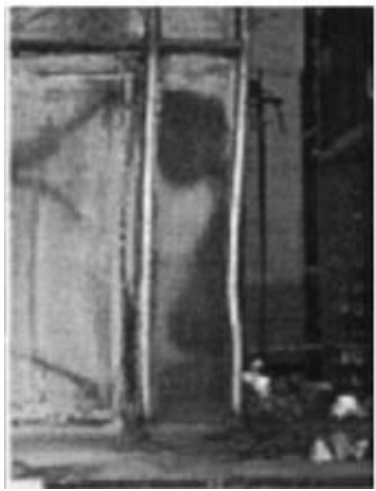

Fig .6 - yielding of the first floor column in the experiment [10] 


\section{Modelling and Method of Study}

In this study, several samples of single-story-one-way conventional steel shear walls were first designed according to the LRFD method considering AISC341 Guideline No. 20 requirements [11]. Then, to study the behavior of steel plate shear walls connected to frame beam only, plate at designed SSW was separated from side columns and only connected to the overhead beam. It should be noted that the distance between plate edge and boundary columns was much selected to be very low. The geometrical dimensions and the mechanical properties of the boundary members and infill plates in both cases are the same. To model all boundary members and steel plates in ABAQUS software [12], the shell element (S4R) was used, 2a quadruple element with reduced integration. Each node of this element has 6 degrees of freedom, that is, 3 degrees of freedom of movement and 3 degrees of transitional freedom. In this research, by applying an initial imperfection according to the first buckling mode in the model, the possibility of infill plate buckling was provided. It also prevents off-screen deformation of the columns from preventing curvature on the page. Von Mises's yield level was also selected as the yield criterion. In predicting the desired behavior, nonlinear geometric and nonlinear effects of the material are also considered. For die sheets LYP100 steel with $100 \mathrm{MPa}$ yield stress and for boundary members including beams and columns, St52 with $360 \mathrm{MPa}$ yield stress was used.

To investigate the behavior of the samples, these samples were considered in 4 groups with different lengths. The axis to axis distance of the columns in groups A, B, C, and D is 4.5, 5.5, 6.5 , and $7.5 \mathrm{~m}$, respectively. Group D, with a length of $7.5 \mathrm{~m}$, represents a wide steel shear wall. Also, the height of all samples was considered to be $3.2 \mathrm{~m}$. The geometric characteristics of the studied samples in the present study are presented in Table 1.

Tab. 1 - Geometric characteristics of the samples studied in the present study

\begin{tabular}{|c|c|c|c|c|c|}
\hline model & $\begin{array}{c}\text { Width } \\
(\mathrm{m})\end{array}$ & $\begin{array}{c}\text { Height } \\
(\mathrm{m})\end{array}$ & $\begin{array}{c}\text { Plate } \\
\text { thickness } \\
(\mathrm{mm})\end{array}$ & beam & column \\
\hline A & 4.5 & 3.2 & 4 & $\mathrm{H} 400-250-35-25$ & Box $370 \times 370 \times 35 \times 35$ \\
\hline B & 5.5 & 3.2 & 4 & $\mathrm{H} 400-250-35-25$ & Box $370 \times 370 \times 35 \times 35$ \\
\hline C & 6.5 & 3.2 & 4 & $\mathrm{H} 400-250-35-25$ & Box $370 \times 370 \times 35 \times 35$ \\
\hline D & 7.5 & 3.2 & 4 & $\mathrm{H} 400-250-35-25$ & Box $370 \times 370 \times 35 \times 35$ \\
\hline
\end{tabular}

In this paper, by separating the connection of the plate to the beam or columns, their behavior under cyclic loads was investigated. As shown in Figure 7, the lateral load is applied to the column. The foot of the wall was attached to the ground. To simulate this in ABAQUS software, the transitional and rotational displacement of the lower points of the wall in three directions was prevented. To study the behavior of studied models, hysteresis analysis according to the SAC loading protocol was utilized. (Figure 8) [13]. In this study, the loading continued until the ultimate strength decreased by at least $20 \%$ compared to the maximum strength. 


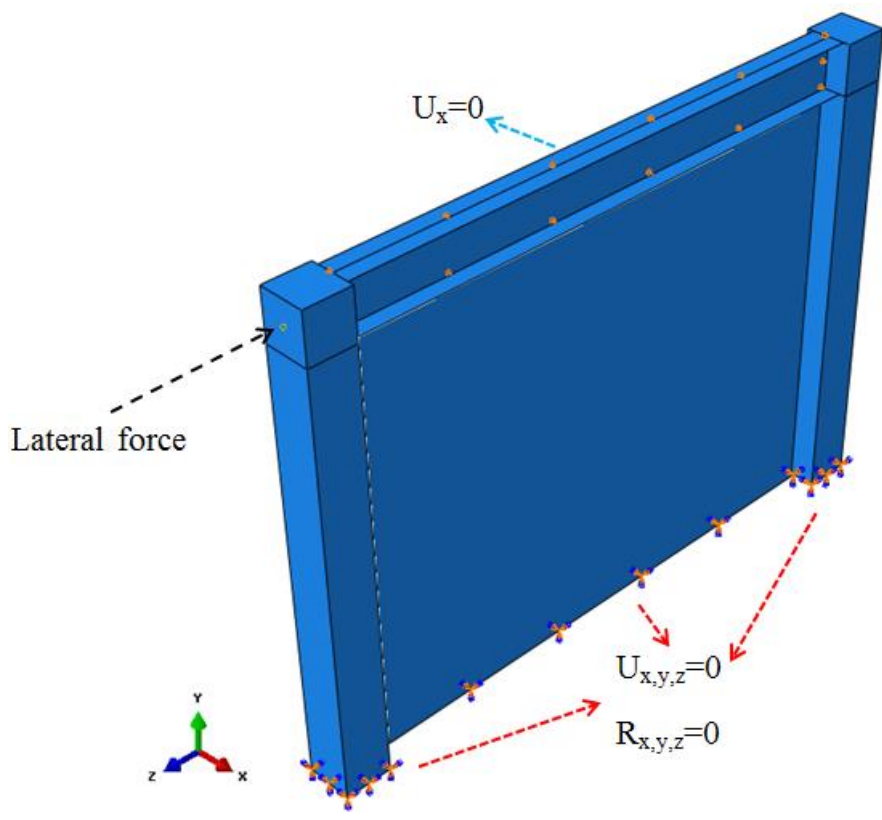

Fig. 7 - Boundary conditions of the studied samples

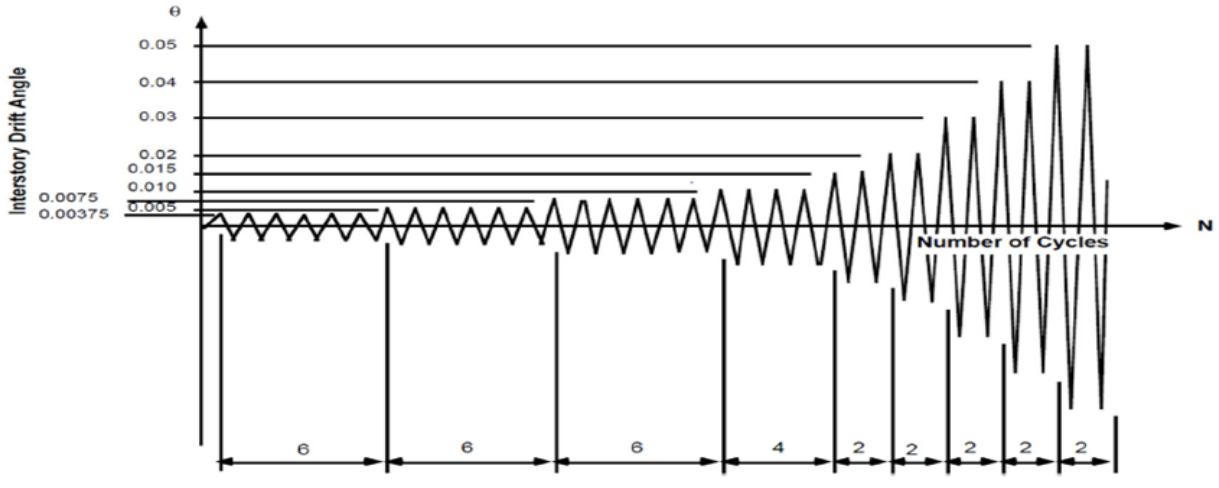

Fig. 8 - Loading protocol based on SAC [13]

In the following sections, the word "Full“ represents steel shear walls with full connection and the symbol "BF" refers to steel shear wall connected to frame column. Also, the symbol "CF" refers to the steel shear wall connected to the frame beam. For example, the CF model in group $A$ is shown in Fig. 9. As can be seen, there is no connection between plate and columns in this model along column height, and the plate is connected to the beam. It should be noted that the web plate is attached to the boundary members, including the beam and column, using welding. In order to simulate this problem in ABAQUS software, the plates were tied to the boundary elements in the interaction module in ABAQUS. 


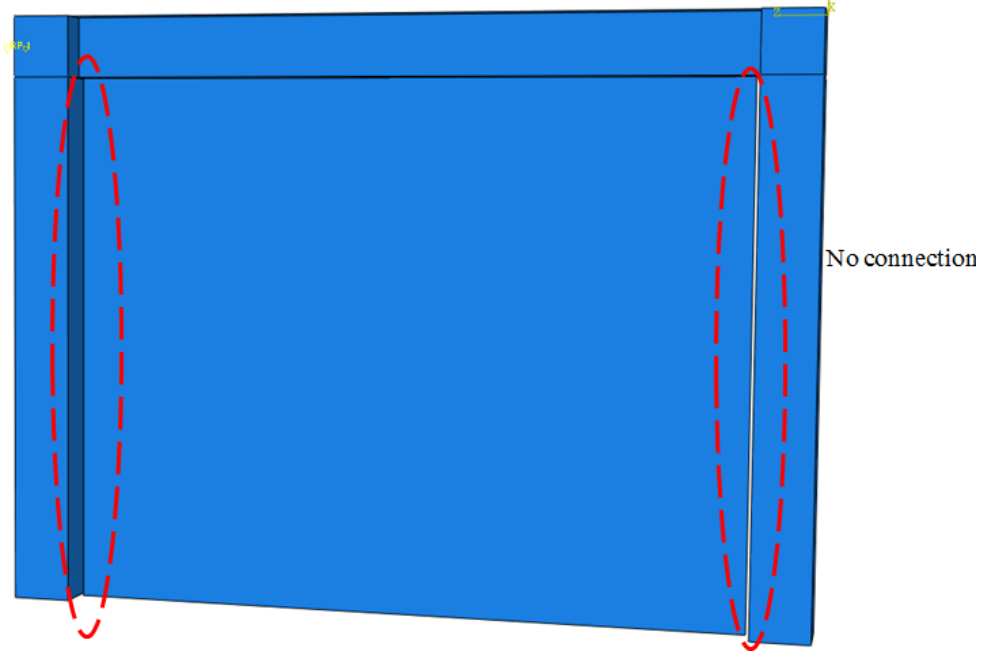

Fig. 9 - No connection between plate and columns in CF model

\section{RESULTS}

\section{Shear capacity}

Maximum shear capacity of the studied samples in different models is presented in Table 2.

Tab. 2 - Maximum shear capacity of the studied samples

\begin{tabular}{|c|c|c|c|c|c|}
\hline Group & Full & CF & BF & $\begin{array}{c}\text { The difference between } \\
\text { the maximum strength of } \\
\text { the CF sample and Full } \\
(\%)\end{array}$ & $\begin{array}{c}\text { The difference } \\
\text { between the } \\
\text { maximum strength of } \\
\text { the BF sample and } \\
\text { Full (\%) }\end{array}$ \\
\hline A & 4402.4 & 3429.9 & 3342.9 & 22.0 & 24.0 \\
\hline B & 4593.9 & 3608.3 & 3433.2 & 21.4 & 25.2 \\
\hline C & 4710.3 & 3711.1 & 3398.4 & 21.2 & 27.8 \\
\hline D & 4884.0 & 3927.2 & 3563.7 & 19.5 & 27.0 \\
\hline
\end{tabular}

According to Table 2, the strength of the Full samples in all groups is higher than the CF and BF samples. The difference between maximum strength of Full and CF samples in groups A, $\mathrm{B}, \mathrm{C}, \mathrm{D}$, and $\mathrm{E}$ are $22.0,21.4,21.2$, and $19.5 \%$, respectively. It is noteworthy that with the increasing the width of the samples, differences between maximum strength of Full and CF samples slightly decreased. In addition, the difference between maximum strength of Full and BF samples in groups $A, B, C, D$, and $E$ are $24.0,25.2,27.8$, and $27.0 \%$, respectively. It is noteworthy that the strength of the BF samples is $2.6,5.1,9.2$, and $10.2 \%$ lower than the CF samples in groups $A, B, C$, and $D$, respectively. On the other hand, when the infill panel is only connected to beams, it has higher strength than the corresponding sample.

\section{Beam behavior}

In Figure 10, maximum bending moment of beam during lateral loading is shown. 
A

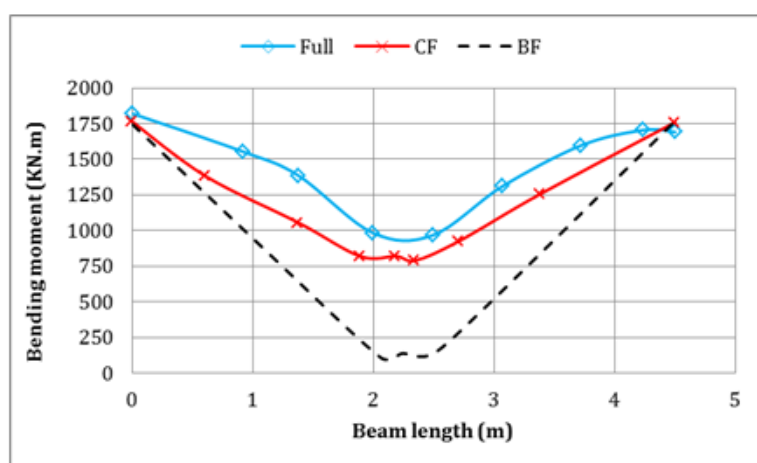

C

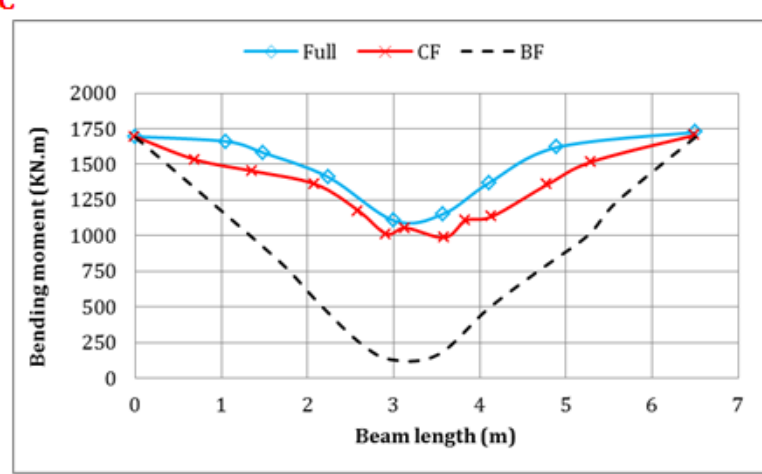

B

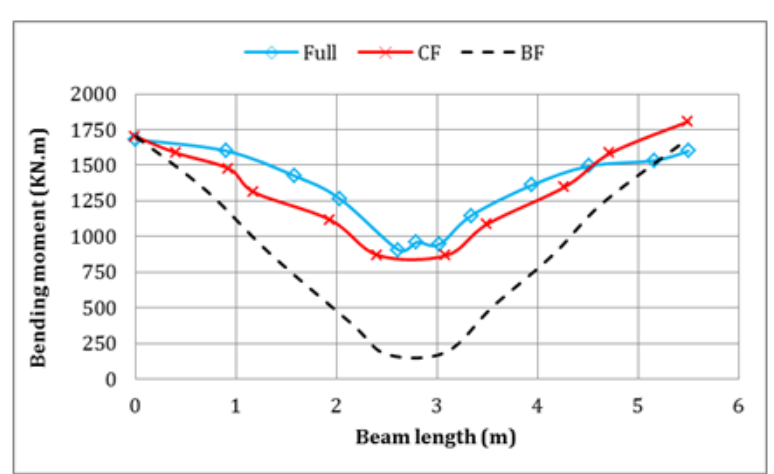

D

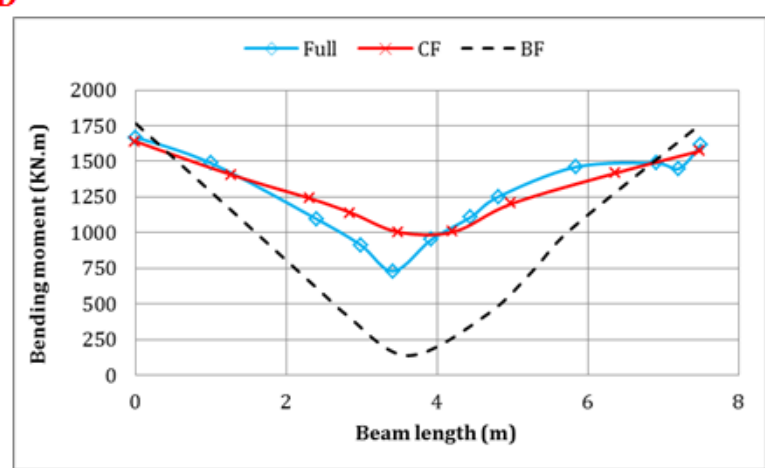

Fig. 10 - Comparison between the maximum bending moment of the beam during loading in different modes

As can be seen, the maximum bending moment occurred at both ends of the beam. Totally, the maximum bending moment at the end of the beam of Full, CF, and BF models are approximately equal. The bending moment of the beam in all sections of the beam length in the Full sample at groups A, B, and C is more than in other samples (except for the two ends). It is noteworthy that in the CF model in group D, the bending moment of the CF model is greater than that of the Full model. This highlights the importance of paying attention to the design of beams in wide steel shear walls in which the plate is attached only to the beam. Another point is that, in BF models, the beam has been subjected to the much less bending moment in different sections except the two ends than in the Full and CF models.

\section{Column behavior}

\section{Investigating the axial force of the column}

In Figure 11, the maximum axial force of the column is presented in different models. 

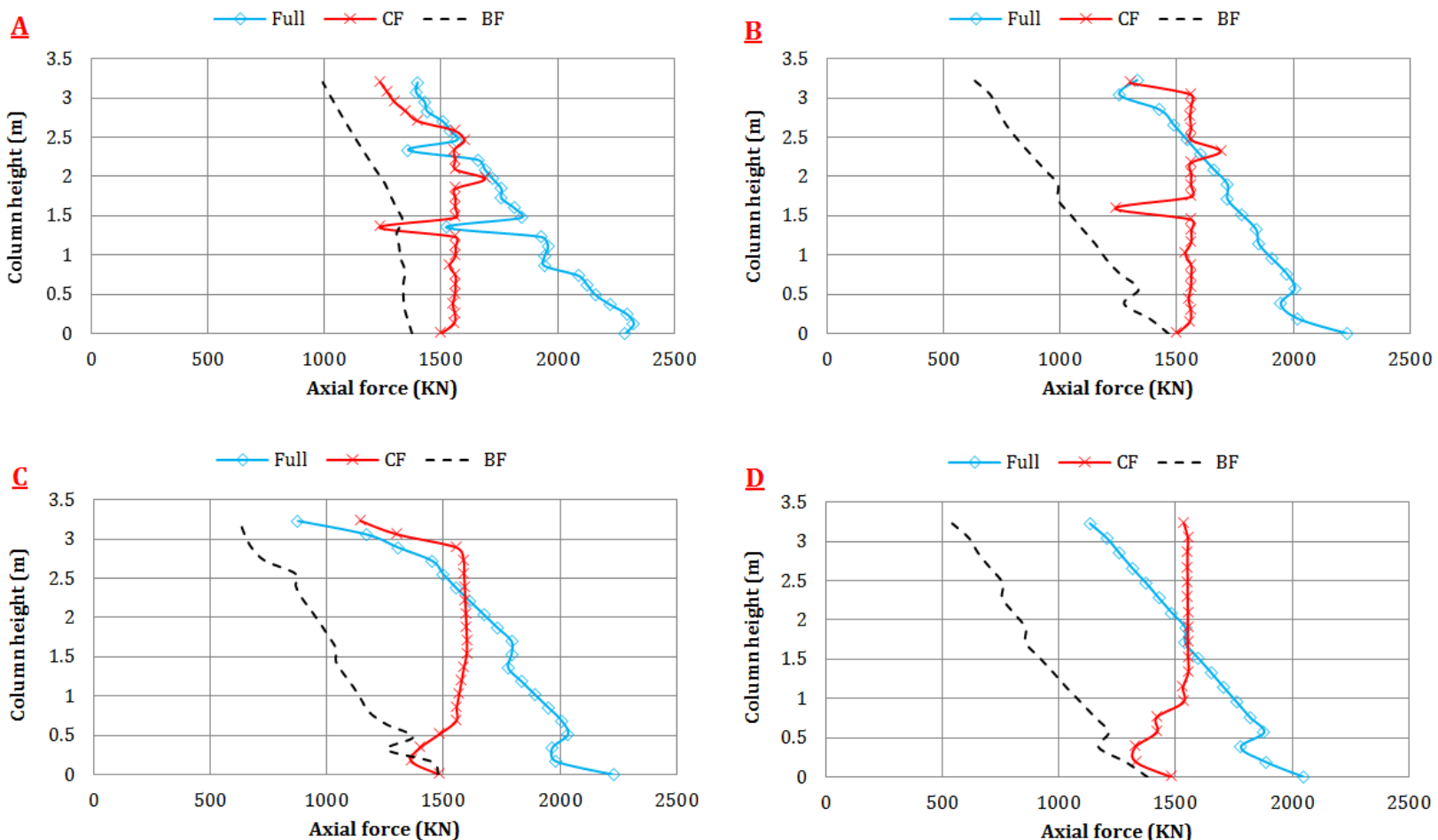

Fig. 11 - Comparison between the maximum axial force of column during loading in different modes

According to Figure11, the first thing to see is that the maximum axial force in the Full sample is greater than that of CF and BF samples. Another result is that in the full sample, the axial force at the foot of the column is maximum, and the axial force in the column is reduced by moving towards the beam ends. However, maximum axial force at the height of the column of the CF model did not occur at the foot of the column but happened in the upper parts. The noteworthy point in this section is that in the upper parts of the column, the maximum axial force was almost constant alongside the column height. The maximum axial force at the foot of the column for CF and BF samples is approximately equal. But in the upper sections, the maximum axial force of the $\mathrm{BF}$ model is lower than that of CF models. Table 3 presents the maximum values of the axial force of the column at the height of the column for different modes in studied groups.

Tab. 3 - Maximum values of column axial force at column height for different modes in different

\begin{tabular}{|c|c|c|c|c|c|c|}
\hline & Full & CF & BF & $\begin{array}{c}\text { difference } \\
\text { between CF } \\
\text { with full models } \\
(\%)\end{array}$ & $\begin{array}{c}\text { difference } \\
\text { between BF } \\
\text { with full } \\
\text { models (\%) }\end{array}$ & $\begin{array}{c}\text { difference } \\
\text { between BF } \\
\text { with CF } \\
\text { models (\%) }\end{array}$ \\
\hline A & 2327 & 2000 & 1928 & 14.05 & 17.14 & 3.6 \\
\hline B & 2232 & 1688 & 1465 & 24.37 & 34.36 & 13.21 \\
\hline C & 2229 & 1601 & 1478 & 28.17 & 33.69 & 7.68 \\
\hline D & 2051 & 1555 & 1380 & 24.18 & 32.71 & 11.25 \\
\hline
\end{tabular}

According to Table 3, it is clear that the difference between the maximum axial force acting on the column in the Full sample compared to the CF model in groups A, B, C, and D, are 14.06, $24.37,28.17$, and $24.18 \%$, respectively. In addition, the difference between the maximum axial force acting on the column in the Full sample compared to the BF model in groups $A, B$, $C$, and $D$ 
CIVIL

ENGINEERING JOURNAL

are $17.15,34.36,33.7$, and $32.7 \%$, respectively. Also, the difference between the maximum axial force in the column in the CF model compared to the BF model in groups A, B, C, and D is 3.6, $13.2,7.7$, and $11.3 \%$, respectively. Therefore, by increasing the width of the span, the difference between the axial forces of the column in the two modes CF and BF has been increased.

\section{Investigating the shear force of the column}

In Figure 12 the maximum shear force of the column is presented in different models.
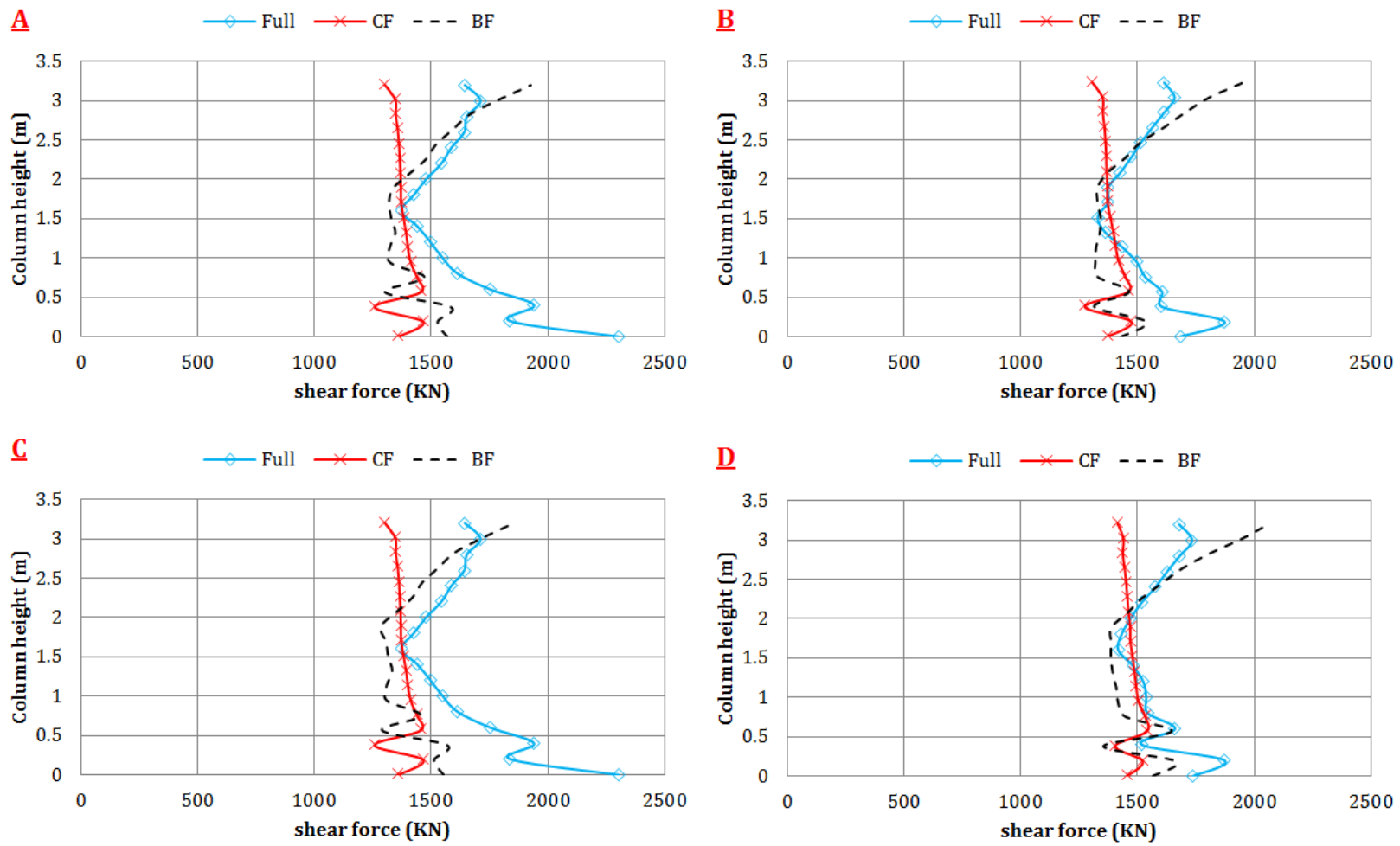

Fig. 12 - maximum shear force acting on the column in different models

According to Figure 12, the maximum shear force of the column in the cf sample is approximately equal along the column. Also, the value of column shear force in the CF sample in all groups is less than the Full and BF models. In groups $A$ and $C$, the maximum shear force of the column along the height of the column for the full model is greater than the other two models. But in groups $B$ and $D$, the maximum shear force of the column along the height of the column for the BF model is more than the other two models. Table 4 presents the maximum values of column shear force at column height for different models in studied groups.

Tab. 4 - Maximum values of column shear force along column height for different modes in different groups

\begin{tabular}{|c|c|c|c|c|c|c|}
\hline Group & Full & CF & BF & $\begin{array}{c}\text { difference } \\
\text { between cf } \\
\text { with full } \\
\text { models (\%) }\end{array}$ & $\begin{array}{c}\text { difference } \\
\text { between BF } \\
\text { with Full } \\
\text { models (\%) }\end{array}$ & $\begin{array}{c}\text { difference } \\
\text { between BF } \\
\text { with CF } \\
\text { models (\%) }\end{array}$ \\
\hline A & 2305 & 1466 & 1927 & 36.39 & 16.39 & 31.44 \\
\hline B & 1874 & 1474 & 1953 & 21.34 & 4.21 & 32.49 \\
\hline C & 2305 & 1466 & 1852 & 36.39 & 19.65 & 26.33 \\
\hline
\end{tabular}




\begin{tabular}{|l|l|l|l|l|l|l|}
\hline $\mathrm{D}$ & 1872 & 1540 & 2063 & 17.73 & 10.20 & 33.96 \\
\hline
\end{tabular}

As can be seen in Tab. 4, the difference between the maximum shear force acting on the column in the Full model compared to the cf model in groups A, B, C, and D are 36.39, 21.34, 39.36 , and $17.73 \%$, respectively. In addition, the difference between the maximum shear force acting on the column in the Full model compared to the BF model in groups $A, B, C$, and $D$ is $16.39,4.21,19.65$, and $10.2 \%$, respectively. Also, the difference between the maximum shear force in the column in the CF model compared to the BF model in groups A, B, C, and D is 31.44 , $32.49,26.33$, and $33.96 \%$, respectively.

\section{DEFORMATION}

Deformation of models in group $A$ is presented in Figure 13.
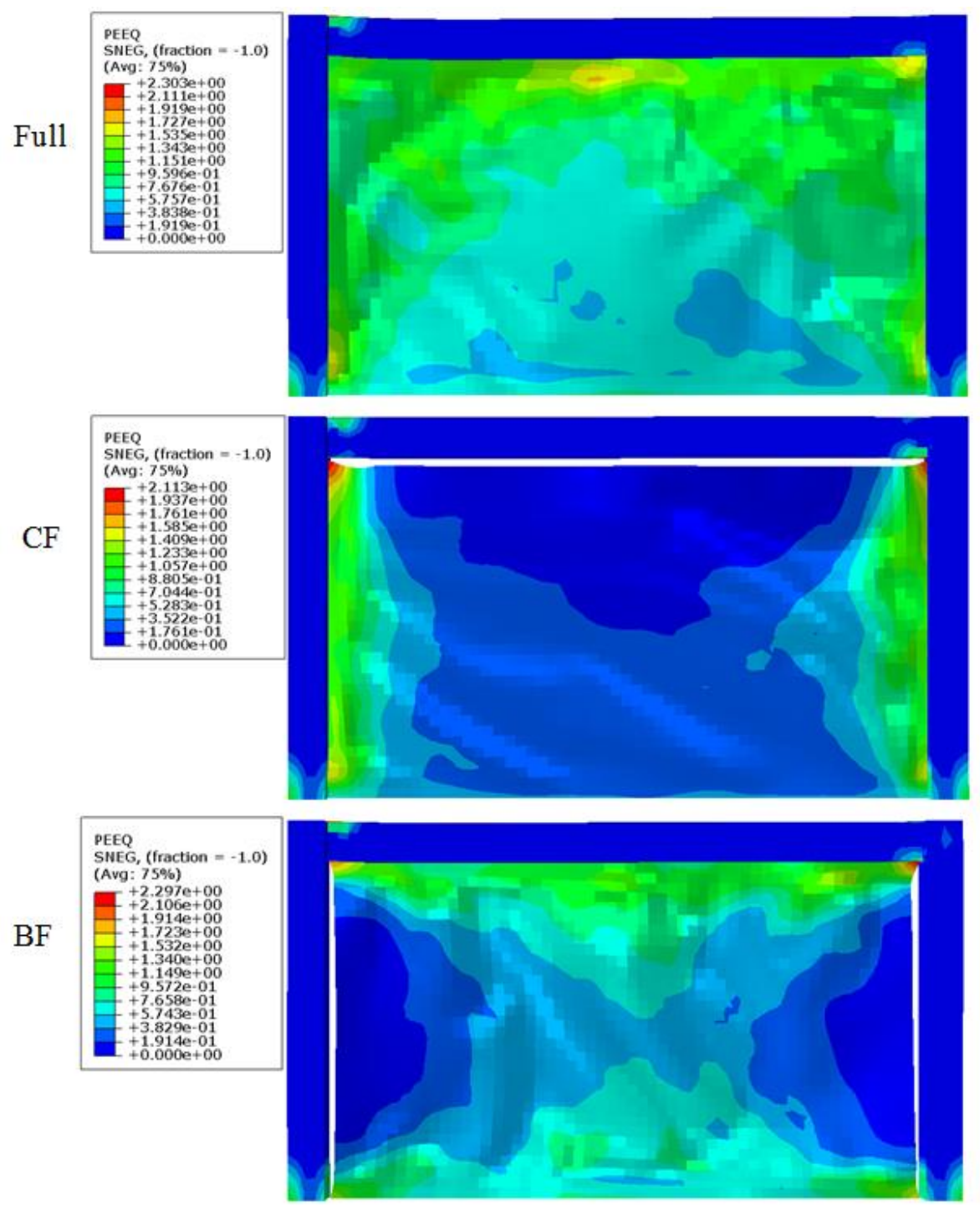

Fig. 13 - Equivalent plastic strain (PEEQ) contours of $A$ group 


\section{CONCLUSION}

In this study, the behavior of steel shear walls by connecting the infill plate to only one of the boundary members was investigated. In other words, the behavior of steel shear walls with different conditions of plate connection to boundary members was investigated. Therefore, four groups of steel shear walls with different lengths were considered, and then in these four groups, three different modes of plate connection to the boundary members were considered. In the first case, the plate was attached to the surrounding beams and columns, traditionally. In the second case, the plate was attached only to the beam, and in the third case, the plate was attached only to the columns. To investigate the behavior of the samples studied in this study, quasi-static analysis was used in accordance with the rules of the SAC loading protocol. The main obtained results from this study are as follows:

$\checkmark$ When the plate is attached only to the beam, the strength of the steel shear wall in the samples of groups A, B, C, and D is $22.0,21.4,21.2$, and $19.5 \%$ lower than the sample with full connection, respectively.

$\checkmark$ When the plate is attached only to the columns, the strength of the steel shear wall in the samples of groups $A, B, C$, and D is $24.0,25.2,27.8$, and $27.0 \%$ lower than the sample with full connection, respectively.

$\checkmark$ The strength of the specimens with the connection of the plate only to the beam is higher than the specimens with the connection of the plate only to the columns. This difference is increased by increasing the width of the steel shear wall.

$\checkmark$ The maximum bending moment of the beams in the studied samples in different groups with different plate connections to the boundary members are almost equal to each other. The maximum bending moment of the beams in the studied samples in different groups with different connections of the sheet to the boundary members are almost equal to each other. However, in beams in which the plate is attached only to the columns, the beam has a less bending moment in different sections except for the end of beams.

$\checkmark$ The maximum axial force acting on columns in steel shear walls with Full connection is considerably higher than in BF and CF samples. The maximum axial force of columns in CF models is equal to or slightly less than that of BF models. The interesting point here is that the axial forces of the column in the CF samples are almost constant along the height of the column. While in other specimens, it decreased almost linearly with increasing column height.

$\checkmark$ The shear force of the column in all groups in the BF sample is less than the full and CF samples. By comparing the shear force in Full and CF samples, it was found that no special relationship is established

\section{REFERENCES}

[1] P.A. Timler, C.E. Ventura, H. Prion, R. Anjam, Experimental and analytical studies of steel plate shear walls as applied to the design of tall buildings, The Structural Design of Tall and Special Buildings 7 (1998) 233-249.

[2] A. Astaneh-Asl, Seismic Behavior and Design of Steel Shear Walls, Steel Tips, Structural Steel Educational Council, Technical Information and Product Service, 2001.

[3] A. Jahanpour, J. Jön\&TDREFS;sson, H. Moharrami, Seismic behavior of semi-supported steel shear walls, Journal of Constructional Steel Research 74 (2012) 118-133.

[4] A. Jahanpour, H. Moharrami, Evaluation of behavior of the secondary columns in semi-supported steel shear walls, Thin-Walled Structures 93 (2015) 94-101.

[5] M. Xue, L.W. Lu, Monotonic and cyclic behavior of in-filled steel shear panels, in: Proc. Seventeenth Czech and Slovak International Conf. on Steel Structures and Bridge, 1994. 
CIVIL

ENGINEERING JOURNAL

[6] M. Xue, L.W. Lu, Influence of steel shear wall panels with surrounding frame members, in: Proc. SSRC Annual Technical Session, 1994.

[7] I. Choi and H. Park, CYCLIC TEST FOR FRAMED STEEL PLATE WALLS WITH VARIOUS INFILL PLATE DETAILS, the $14^{\text {th }}$ World Conference on Earthquake Engineering

October 12-17, 2008, Beijing, China

[8] Lanhui Guo, Qin Rong, Xinbo Ma, and Sumei Zhang, Behavior of Steel Plate Shear Wall Connected to Frame Beams Only, International Journal of Steel Structures December 2011

[9] In-Rak Choi and Hong-Gun Park, Ductility and Energy Dissipation Capacity of Shear-Dominated Steel Plate Walls, J. Struct. Eng. 2008.134:1495-1507

[10] Hong-Gun Park; Jae-Hyuk Kwack; Sang-Woo Jeon; Won-Ki Kim; and In-Rak Choi, Framed Steel Plate Wall Behavior under Cyclic Lateral Loading, J. Struct. Eng. 2007.133:378-388

[11] Sabelli R, Bruneau M. Design guide 20: steel plate shear walls, American Institute of Steel Construction. Chicago, IL, USA 2007.

[12] ABAQUS Version 14.1. (2014). ABABUS user's manual, Hibbitt, Karlsson, and Sorenson Inc. (HKS), Pawtucket, R. I, USA

[13] H. Krawinkler, Loading histories for cyclic test in support of performance assessment of structural components, in: 3rd International Conference on Advances in Experimental Structural Engineering, San Francisco, 2009. 